\title{
LAPANGAN TEMBAK WASAKA DI BANJARMASIN
}

\author{
Aulia Noor Maulida \\ Program Studi Teknik Arsitektur Fakultas Teknik Universitas Lambung Mangkurat \\ auliiamaulida@gmail.com \\ J.C. Heldiansyah \\ Program Studi Teknik Arsitektur Fakultas Teknik Universitas Lambung Mangkurat \\ jcheldiansyah@ulm.ac.id
}

\begin{abstract}
ABSTRAK
Kalimantan Selatan selama 10 tahun terakhir memiliki atlet menembak yang cukup potensial untuk berlaga di tingkat nasional maupun internasional. Hal tersebut tidak diimbangi dengan fasilitas yang memadai yang dapat mewadahi segala aktivitas latihan para atlet. Latihan merupakan peran penting dalam meraih prestasi, akan tetapi saat ini tempat berlatih tidak mendukung atlet untuk memaksimalkan potensinya. Arsitektur perilaku sebagai metode penyelesaian masalah agar dapat memaksimalkan potensi atlet dimulai dari 3 bagian latihan yaitu emosi, kognisi dan performance. Lapangan Tembak Wasaka didesain agar atlit sebagai pengguna utama dapat melakukan latihan dengan konsep metamorfosis yang menyiapkan atlet secara emosi dan kognisi. Dengan konsep ini, area akan terbagi tiga zona yaitu transisi, persiapan, dan zona inti.
\end{abstract}

Kata Kunci: Lapangan Tembak, Menembak, Arsitektur Perilaku, Atlit

\begin{abstract}
South Kalimantan for the past 10 years has shooting athletes that have potential to compete national and international. But it is not balanced with facilities such as there is no shooting range that can accommodate all training activities of athletes. Training is the most important thing in achievement, but in fact the current place for training does not support athletes to maximize their potential. Behavior architecture as a method to solve or maximize potential of athletes starts with three parts of training: emotion, cognition and performance. Wasaka Shooting Range designed to make athletes as main users have training with metamorphosis concepts that prepare the athletes emotionally and cognitively. With this concept, the area is divided into three zones which is transition, prepare and main zone.
\end{abstract}

Keywords: Shooting Range, Shooting, Behavior Architecture, Athletes

\section{PENDAHULUAN}

Berbagai jenis olahraga dapat menjadi pilihan untuk mengembangkan potensi seseorang, salah satunya adalah olahraga menembak. Olahraga menembak kini kian berkembang dan mulai diminati berbagai kalangan karena bersifat dinamis dan menantang. Sesuai dengan perkembangan zaman, hobi, dan gaya hidup, menembak dengan menggunakan senjata api maupun senapan angin menjadi salah satu olahraga pilihan yang dapat berprestasi. Olahraga menembak menjadi salah satu cabang pertandingan multi event di PON, SEA Games, Asian Games, dan Olimpiade. Provinsi Kalimantan Selatan memiliki 126 atlet menembak yang tersebar di berbagai kabupaten diantaranya Banjarmasin, Banjarbaru, Tanah Bumbu, Kotabaru, Hulu Sungai Selatan, Hulu Sungai Utara, Tanjung dan Tapin. Dari 126 atlit, 47 diantaranya merupakan atlet dari Kota Banjarmasin. Kalimantan Selatan memiliki Atlet Provinsi (Tim Wasaka) sebanyak 20 atlet dan 5 diantaranya sekaligus sebagai Atlet Nasional 
(Tim Indonesia). Dari 20 atlet provinsi tersebut 17 diantaranya berasal dari Kota Banjarmasin.

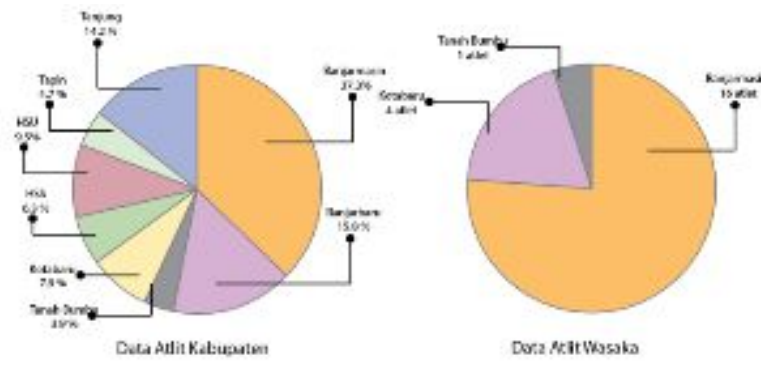

Gambar 1 Diagram Data Atlit Kalsel Sumber : Pengda Perbakin Kalimantan Selatan

10 Tahun Belakangan ini Kalimantan Selatan merupakan salah satu provinsi yang unggul di Indonesia dalam olahraga menembak. Dari PON Riau 2012 hingga PON Jabar 2016 Kalimantan Selatan mendapat peningkatan yang signifikan dari olahraga menembak. Pada tahun 2012 Cabang Menembak meraih 1 emas dari 5 emas yang diraih keseluruhan dan pada tahun 2016 cabor menembak memperoleh 4 emas dari 7 emas dari keseluruhan.

\begin{tabular}{|c|c|c|c|c|c|c|}
\hline \multicolumn{6}{|c|}{ Peroiehan medali PON XVIE 2012} & \multirow[b]{2}{*}{ Tots: } \\
\hline Peringeat & Stahus: & Provins! & 0 & 0 & 0 & \\
\hline $1 \mathrm{a}$ & $\Delta \theta$ & Kaimartin Furgah & a & 4 & e & 16 \\
\hline 19 & $\nabla \mathrm{t}$ & Kaimantas Seknan & 5 & 12 & 18 & 36 \\
\hline 20 & - & Maulas & 4 & 10 & 5 & 19 \\
\hline 21 & a 1 & Eartien & 4 & B & 18 & 39 \\
\hline 22 & As & Kepulauan Rive & 4 & 1 & 5 & 10 \\
\hline 2 & $\Delta$; & Nuka Tesqgera Trmut & 3 & 9 & 4 & 17 \\
\hline 24 & $\nabla 9$ & danti & 3 & 8 & 20 & 31 \\
\hline 25 & $\nabla_{2}$ & Acoh: & 3 & 5 & 18 & 26 \\
\hline 28 & $\nabla 7$ & Pusua Berz: & 3 & 3 & 11 & 17 \\
\hline 27 & $\boldsymbol{7} 10$ & Eu/awed Tenograra & 3 & 0 & 2 & 5 \\
\hline $2 a$ & $\Delta 1$ & Bengka Betiung & 2 & 3 & 4 & $\theta$ \\
\hline $\boldsymbol{2}$ & $\Delta 3$ & Gorontes & 2 & 1 & 1 & 4 \\
\hline 30 & A t & Sulawed Tengah & $t$ & 1 & $t$ & 3 \\
\hline 9: & $\boldsymbol{\gamma}_{3}$ & Eescloulu & a & 2 & 4 & B \\
\hline 32 & $\mathrm{~T} z$ & Ma Lbe Ltara & 0 & 0 & 1 & 1 \\
\hline 33 & - & Sulaweel Bant & 0 & 0 & 0 & 0 \\
\hline Total & & & noo & sea & ras & 1963 \\
\hline
\end{tabular}

\begin{tabular}{|c|c|c|c|c|}
\hline No Kontingen & tmas & Perak & Perunegu & Total \\
\hline IIAWA BARAT & 198 & 137 & 140 & 465 \\
\hline 2. LAWA TIMTR. & 123 & 123 & 116 & 36: \\
\hline 3 DEI AAKARTA & 118 & 115 & 112 & 345 \\
\hline 4. JAWA TENGAH & 26 & 49 & 7. & $147^{4}$ \\
\hline SKALDANTANTMER. & 21 & 30 & 60 & 111 \\
\hline $63 \mathrm{ML}$ & 18 & 19 & 33 & 70 \\
\hline 7inat & 16 & 25 & 24 & 65 \\
\hline 8 SLMAZERA LTAZA & 15 & ts & 30] & 60) \\
\hline 9 PAPLA & 16 & 12 & 24. & 30 \\
\hline 10 D YOGYAKARTA & 11 & 19 & 19] & 45 \\
\hline 11 LAMPLXG & II] & 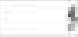 & 13 & 29 \\
\hline 12 SLLAWESI SELATAN & 10 & 20 & 18. & 48 \\
\hline 13 SLMATERA BABAT & 9 & 9 & 17 & 35 \\
\hline 14 BANTEN & 9 & ? & 22. & 38 \\
\hline 15 KALLMNTAN STLATAN & 7 & 6 & 12 & 3 \\
\hline 16 NLSA TENGGARA BARAT & 7 & $s$ & 15 & 27. \\
\hline
\end{tabular}

Gambar 2 Perolehan Medali PON 2012 dan 2016

Hingga dari data tersebut atlet Kalimantan Selatan banyak yang mampu bertanding di kancah nasional maupun internasional. Hal ini terbukti Kalimantan Selatan mempunyai potensi dibidang olahraga menembak dan diperkuat dengan pernyataan dari pihak KONI Provinsi bahwa olahraga menembak menjadi cabang olahraga unggulan kedua setelah gulat untuk bertanding di tingkat PON. Meskipun banyak memiliki atlet berpotensi PENGDA PERBAKIN Kalimantan Selatan tidak memiliki lapangan yang standar dan baru tersedia lapangan $10 \mathrm{~m}$ yang dibuat seadanya. Dikarenakan $90 \%$ atlet provinsi berdomisili di Banjarmasin maka site yang terpilih merupakan milik dari Bapak Herman Candra yang berlokasi di Jalan Belitung darat samping SPBU Belitung.

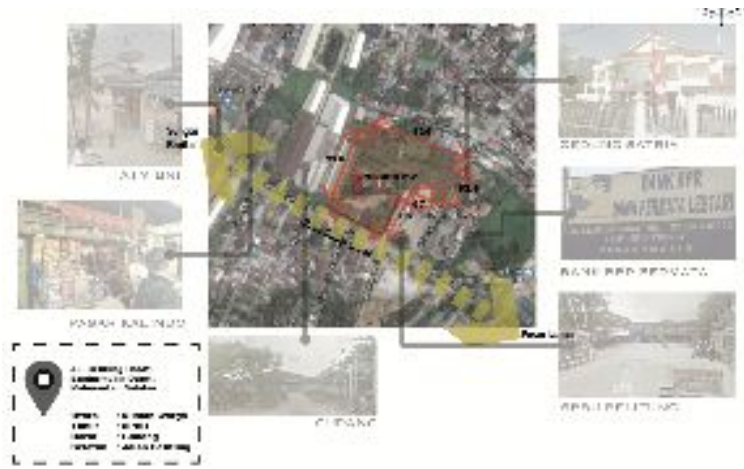

Gambar 3 Site

Sumber : Analisis Penulis, 2019 
Dengan demikian diperlukannya wadah untuk para atlet untuk berlatih secara intens. Dilihat dari cabang apa saja yang diunggulkan Kalimantan Selatan, semua merupakan cabang yang aman tidak memerlukan free area sehingga aman dibangun ditengah kota antara lain Rifle/pistol 10m, rapid, 3 position, dan running target.

Tabel 1 Daftar Cabang Olahraga Menembak

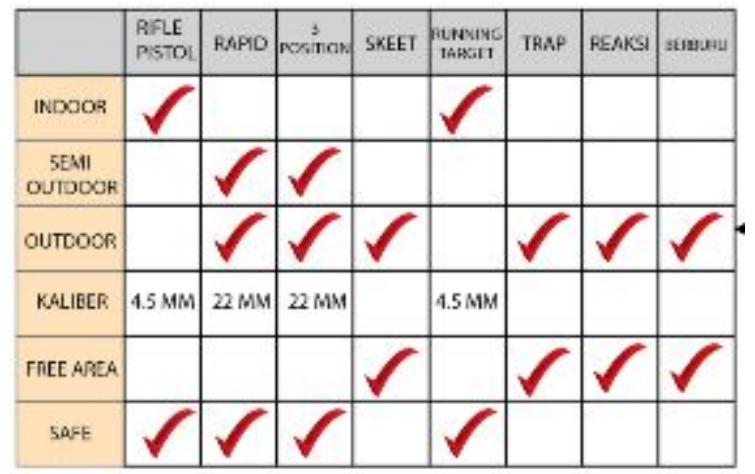

Demikian dapatlah dikatakan bahwa potensi Kalimantan Selatan terhadap olahraga menembak sangat tinggi. Fasilitas yang memadai menjadi salah satu aspek penting untuk mendukung olahraga menembak secara optimal. Dengan adanya Lapangan Tembak Wasaka diharapkan dapat meningkatkan prestasi atlet.

\section{PERMASALAHAN}

Performa atlet dalam latihan maupun pertandingan dituntut agar menampilkan secara maksimal. Faktor penunjang performa atlet antara lain :

- Tingkat fokus yang tinggi

- Pengontrolan emosi yang bagus

- Ketelitian

- Teknik

- Fisik

Tingkat fokus yang tinggi adalah hal yang paling penting dan mendasar dalam performa atlet. Dengan tingkat fokus yang tinggi dapat menghasilkan score tinggi. Pencapaian score cukup tinggi dapat meningkatkan prestasi atlet dan dapat mengembangkannya menjadi lebih bagus lagi. Kebanyakan Lapangan Tembak saat ini tidak menganggap lingkungan sebagai salah satu hal penting yang dapat meningkatkan tingkat fokus pada atlet, padahal lingkungan dapat menjadi salah satu faktor eksternal dalam mengembangkan tingkat fokus atlet.
Berdasarkan uraian latar belakang yang dipaparkan di atas maka dapat disimpulkan permasalahan arsitekturalnya adalah bagaimana rancangan Lapangan Tembak Wasaka di Banjarmasin yang tidak hanya mewadahi aktivitas latihan dan bertanding, namun juga sebagai salah satu penunjang performa atlet? Dengan menggunakan metode arsitektur perilaku dapat menganalisa fungsi bangunan, fungsi ruang terhadap atlet yang akan melaksanakan latihan maupun pertandingan.

\section{TINJAUAN PUSTAKA}

\section{A. Tinjauan Judul}

\section{Lapangan tembak}

Lapangan Tembak terdiri atas dua (2) suku kata yakni Lapangan dan tembak. Menurut KBBI (Kamus Besar Bahasa Indonesia) lapangan tembak adalah tempat atau tanah yang luas untuk melepaskan peluru.

\section{Wasaka}

Wasaka merupakan singkatan dari Waja Sampai Kaputing yang diambil dari pepatah masyarakat banjar yaitu "Haram Manyarah Waja Sampai Kaputing". Pepatah ini mengandung arti apabila memiliki pekerjaan maka haruslah dituntaskan hingga sempurna. Setiap orang bertanggung jawab untuk menuntaskan pekerjaannya jangan sampai menggantung. Semboyan ini juga merupakan lambang bahwa penduduk Kalimantan Selatan selalu tekun dalam bekerja melaksanakan segala sesuatu dengan penuh rasa kesanggupan, istiqomah dan konsekuen tanpa berhenti di tengah jalan.

Wasaka juga dipakai untuk nama tim atlet kalsel yang dikategorikan mampu berlaga di ajang bergengsi seperti PON. Nama tim tersebut diharapkan atlet yang dinaunginya pun mampu berjuang semaksimal mungkin.

\section{B. Tinjauan Lapangan Tembak}

\section{Jenis Olahraga Menembak}

Olahraga menembak berdasarkan fungsinya terbagi dua yaitu rekreatif dan edukatif.

- Rekreatif adalah salah satu sarana hiburan sebagai media penyalur stress 
dengan adanya permainan yang memacu adrenalin. Sasaran penggunanya adalah mereka ingin menyalurkan hobi yang dilakukan pada waktu luang. Jenis-jenis olahraga menembak yang rekreatif adalah sebagai berikut: Paintball, Airsoft, Metal silhouette.

- Edukatif adalah mengembangkan potensi bagi atlet elit maupun pemula dalam peningkatan dan pengembangan ilmu menembak. Sasaran penggunanya adalah para atlit elit maupun pemula. Berikut jenis olahraga menembak yang edukatif dinaungi organisasi ISSF :

- ISSF (International Shooting Sport Federation) adalah Organisasi yang menaungi olahraga menembak bersifat Olimpiade yaitu Rifle, Pistol, dan Shotgun. Macam-macam kelas yang dipertandingkan adalah :

Rifle : Air Rifle Match

Pistol : Air Pistol

$$
\begin{aligned}
& \text { : } 3 \text { Position } \\
& \text { : Running Target }
\end{aligned}
$$

Free Pistol

: Rapid Fire

Shotgun : Trap

: Skeet

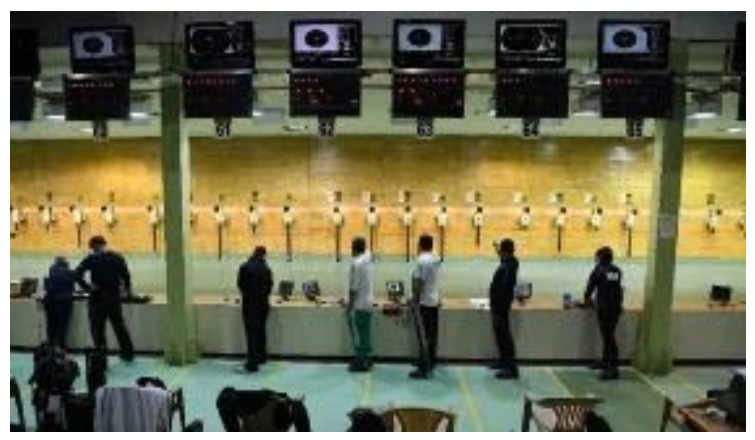

Gambar 4 Air Pistol Event

Sumber : Geo.tv

\section{Struktur Organisasi Pengurus Daerah Perbakin Kalsel 2016-2020}

Tabel 2 Struktur Organisasi Pengda Perbakin Kalsel 2016-2020

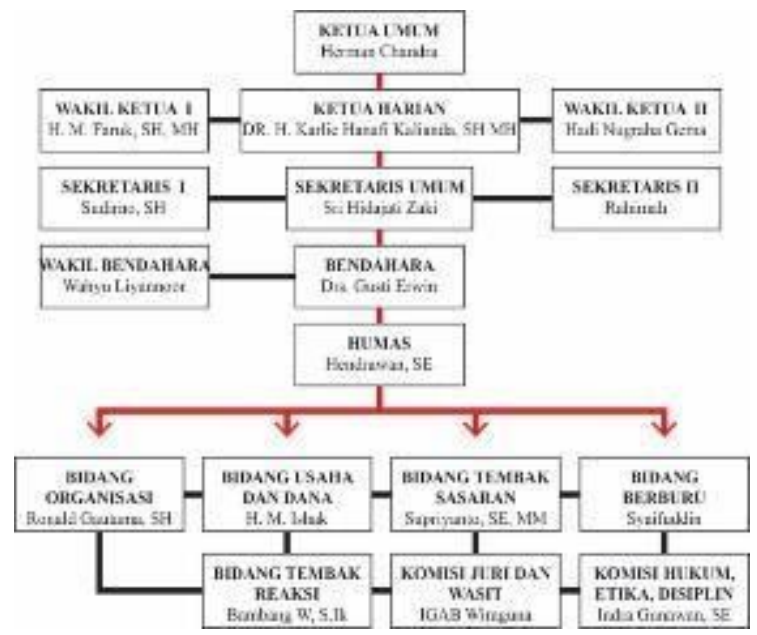

Sumber : Surat keputusan Ketua Umum Pengurus Besar Perbakin Kalimantan Selatan

3. Tipe Lapangan Tembak

- Host a World Shooting Championship

- Host Separate World Shotgun Championships

- Host ISSF World Cups

- Host Continental Championship

Shooting

- Host Continental Games Shooting Events

- Serve as a NationallRegional Shooting Venue

- Serve as a Training Venue

- Serve as a Team or Club Venue

- Host Olympic Games Shooting Events

- ISSF Recommendation

Tipe yang digunakan pada rancangan ini adalah Training Venue.

\section{Ukuran range yang dianjurkan}

\begin{tabular}{|c|c|c|c|c|c|c|}
\hline & \multicolumn{2}{|c|}{ 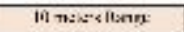 } & \multicolumn{2}{|c|}{ Lim wiker liseng } & \multicolumn{2}{|c|}{ afluten-aric } \\
\hline $\begin{array}{l}\text { Verus } \\
\text { ithesinx }\end{array}$ & $\begin{array}{l}\text { Nos ef } \\
\text { Trus: }\end{array}$ & $\begin{array}{l}\text { Srotialy } \\
\text { Cyusiy }\end{array}$ & $\begin{array}{l}\text { Nust } \\
\text { Tups: }\end{array}$ & $\begin{array}{l}\text { Soz:leh:r } \\
\text { Cyco: }\end{array}$ & $\begin{array}{l}\text { Nond } \\
\text { Tamse }\end{array}$ & $\begin{array}{l}\text { Sretalis } \\
\text { Cylasiy }\end{array}$ \\
\hline 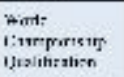 & s: & 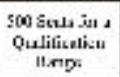 & $\begin{array}{l}\text { blimuge } \\
\text { sti inger }\end{array}$ & 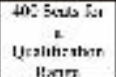 & $\$$ & 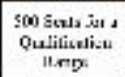 \\
\hline Aint: I I r & $\theta:$ & 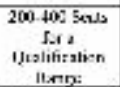 & 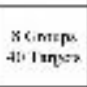 & 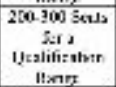 & $\omega$ & 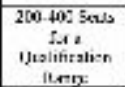 \\
\hline 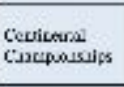 & 4. & 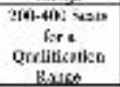 & $\begin{array}{c}\text { 6! } \\
\text { Giouss }\end{array}$ & 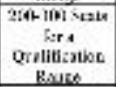 & inst & 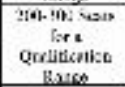 \\
\hline 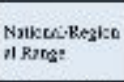 & 4: & 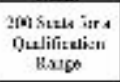 & $\begin{array}{l}610 \\
\text { tirou:s }\end{array}$ & 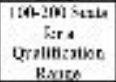 & $4(630$ & 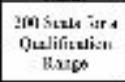 \\
\hline 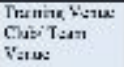 & 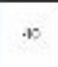 & I:41-3n: & $\begin{array}{c}4.5 \\
\text { Anusu }\end{array}$ & क: & औt: & (1:01-3a: \\
\hline 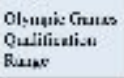 & $\omega$ & 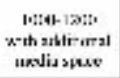 & $\begin{array}{l}8 \text { Grupo } \\
40 \text { Tains: }\end{array}$ & 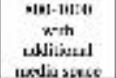 & $\mathrm{mil}$ & 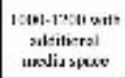 \\
\hline
\end{tabular}

Tabel 3 Standard range

Sumber : ISSF Guidelines For Shooting Venue Planning Edition 2018 : 11-15

\section{Standar Lapangan Tembak \\ a. Lapangan 10 meter}


- Diharuskan lapangan $10 \mathrm{~m}$ berada dalam ruangan dengan menggunakan hawa buatan yaitu AC dan pencahayaan lampu yang tidak silau.

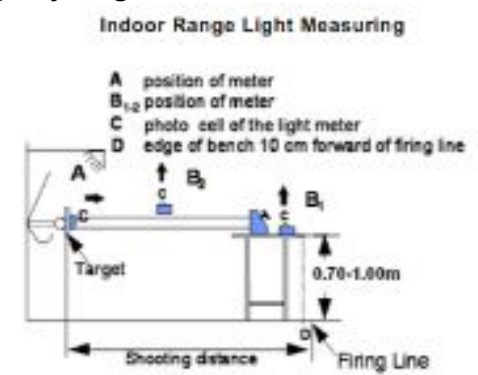

Gambar 5 Indoor Range Light Measuring Sumber : ISSF Rulebook 2017 : 249

- Firing point minimal selebar 1 meter

- Garis merah diletakkan $10 \mathrm{~cm}$ setelah $10 \mathrm{~m}$ firing line

- Jika lapangan multifungsi yang juga dipakai pengguna lapangan 50 meter maka lebar firing point minimal selebar 1.25 meter

b. Lapangan 25 meter

- Pada area atlet harus beratap yang melindungi dari hujan, angin dan matahari.

- Firing point minimal setinggi $2.20 \mathrm{~m}$

- Material harus anti pantul cahaya matahari

\begin{tabular}{|l|l|l|}
\hline Event & Width & Depth \\
\hline $25 \mathrm{~m}$ Rapid Fire Pistol & $1.50 \mathrm{~m}$ & $1.50 \mathrm{~m}$ \\
\hline $\begin{array}{l}25 \mathrm{~m} \text { Pistol } 25 \mathrm{~m} \text { Center Fire Pistol } 25 \mathrm{~m} \\
\text { Standard Pistol }\end{array}$ & $1.00 \mathrm{~m}$ & $1.50 \mathrm{~m}$ \\
\hline
\end{tabular}

\section{Gambar 6 Firing Point Dimensions}

Sumber : ISSF Rulebook 2017 :247

c. Lapangan 50 meter

- Pada area atlet harus beratap yang melindungi dari hujan, angin, dan matahari.

- Firing point minimal lebar 1.25 meter $x$ panjang 2.50 meter

- Jika lapangan multifungsi yang juga dipakai untuk 300 meter maka firing point harus minimal 1.6 meter

\section{Tinjauan Terhadap Perilaku Atlet}

1. Pola Aktivitas Atlet

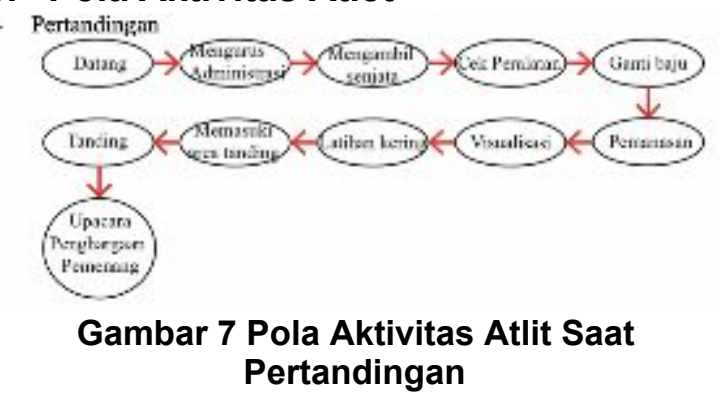

Sumber : Analisis Penulis, 2019

- Latiban

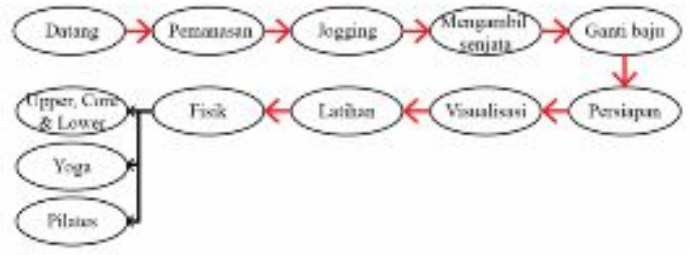

Gambar 8 Pola Aktivitas Atlet Saat Latihan Sumber : Analisis Penulis, 2019

2. Aktivitas Sebelum Menembak

Pemanasan : Perlu dilakukan untuk meningkatkan kekuatan otot dan meminimalkan cedera otot. Biasanya dilakukan secara individu di area dengan tempat latihan atau pertandingan.

Jogging : Lari kecil untuk menyerap oksigen dan memfungsikan jantung lebih bekerja dari biasanya. Hal ini diperlukan untuk melatih kekuatan tingkat fokus dan atlet mampu menurunkan detak jantung secara cepat setelah jogging agar disaat gugup mampu mengendalikan kecepatan detak jantungnya.

- Mengambil senjata : senjata diletakkan pada loker. Sebelum dan sesudah pemakaian senjata harus dikembalikan ke loker.

- Cek peralatan (Check Equipment Control) : Salah satu tahapan sebelum pertandingan menembak atlit wajib lolos pemeriksaan peralatan yang akan digunakan pada saat pertandingan. Jika tidak sesuai standar yang berlaku maka tidak diperbolehkan meneruskan pertandingan.

- Persiapan : menyiapkan segala peralatan seperti memasang stand gun, memasang diopter dll sebelum memasuki area pertandingan. 
- Visualisasi : Visualisasi dilakukan dengan mata tertutup dan duduk. Membayangkan dan mengingat proses-proses menembak dengan baik dan benar dari cara berdiri sampai terjadinya ledakan. Juga mengatur nafas perut agar lebih stabil. Visualisasi dilakukan seperti meditasi.

- Latihan Kering (Dry Firing) : Latihan kering dilakukan sebelum menembak sebagai salah satu visualisasi lanjutan. Mengingat kembali proses-proses menembak namun dilakukan dengan gerakan dan tanpa peluru.

\section{METODE}

Arsitektur Perilaku merupakan salah satu pendekatan dalam merancang. Menurut Snyder dan Catanese (1984), arsitektur berwawasan perilaku adalah arsitektur yang mampu menanggapi kebutuhan dan perasaan manusia yang menyesuaikan dengan gaya hidup manusia didalamnya. Menurut Clovis Heimsath, AIA (1988), kata "perilaku" menyatakan suatu kesadaran akan struktur sosial dari orang-orang, suatu gerakan bersama secara dinamik dalam waktu. Hanya dengan memikirkan suatu perilaku seseorang dalam ruang maka dapatlah kita membuat rancangan.

\section{PEMBAHASAN}

\section{A. Konsep Programatik}

Atlet menembak memiliki beberapa tahapan sebelum memasuki latihan maupun pertandingan. Step-step yang dilakukan sebelum memasuki tahap selanjutnya sangat mempengaruhi performance atlet secara psikis dan fisiologis. Konsep ini diharapkan mampu membuat dari atlit yang belum siap bermetamorfosis menjadi sikap yang diimplementasikan ke dalam bangunan. Faktor yang mempengaruhi performa atlet adalah salah satunya emosi dan kognisi.

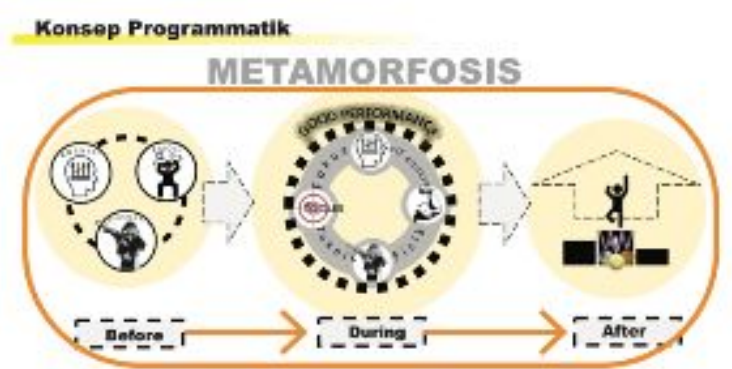

Gambar 9 Konsep Programmatik

\section{B. Konsep Desain}

1. Konsep Emosi

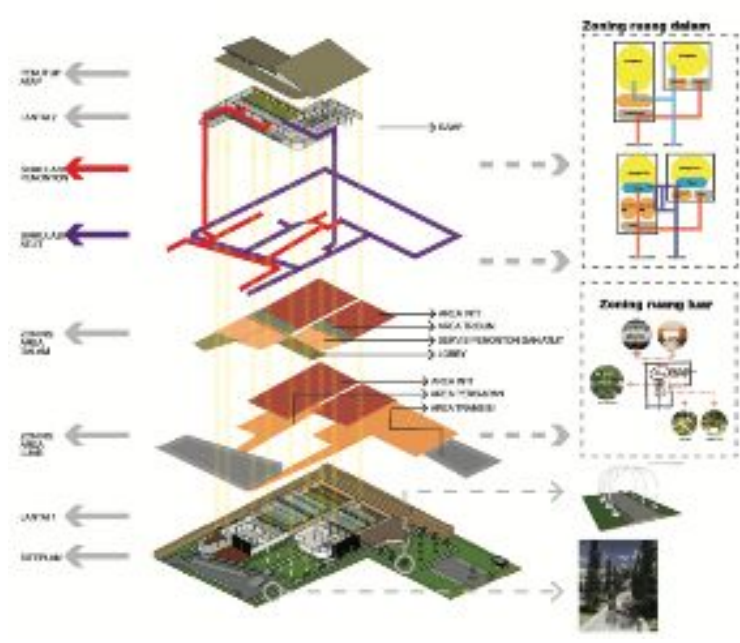

Gambar 10 Konsep Emosi

Konsep Emosi adalah dimana site dirancang agar penggunanya secara silent exercise dapat meredam emosinya dengan pembagian zona menjadi tiga yaitu transisi, persiapan dan zona inti, dengan menambahkan pergola juga pengolahan jogging track.

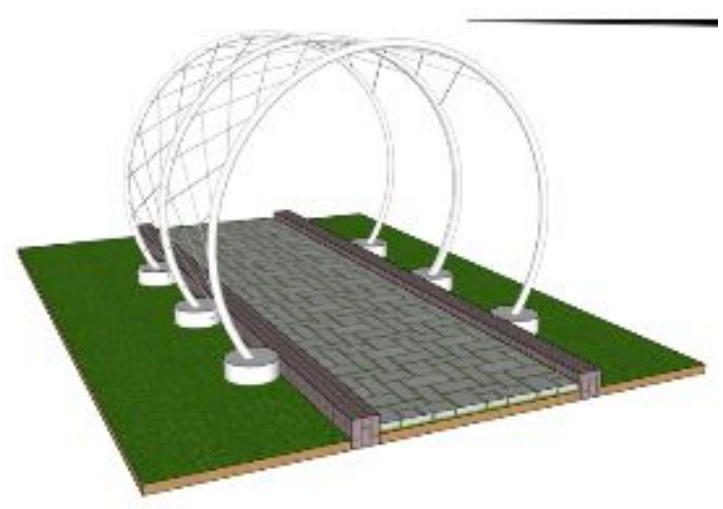

Gambar 11 Pergola 


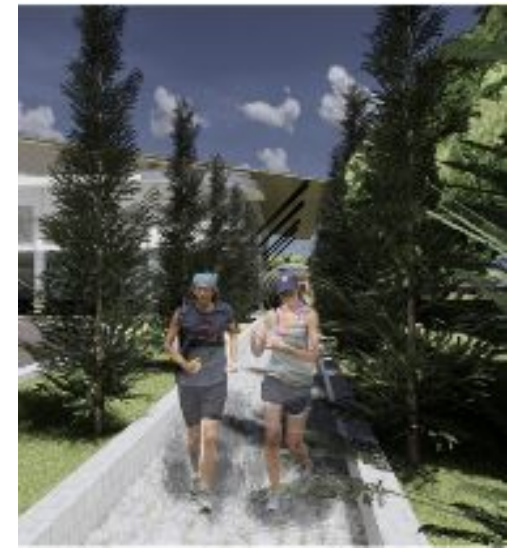

Gambar 12 Jogging Track

\section{Konsep Kognisi}

Atlet berlatih untuk mengasah skill mereka sehingga diperlukan tempat latihan yang tidak hanya mewadahi tempat latihan namun juga memberikan tantangan lebih kepada atlet sesuai tempat yang akan mereka datangi.

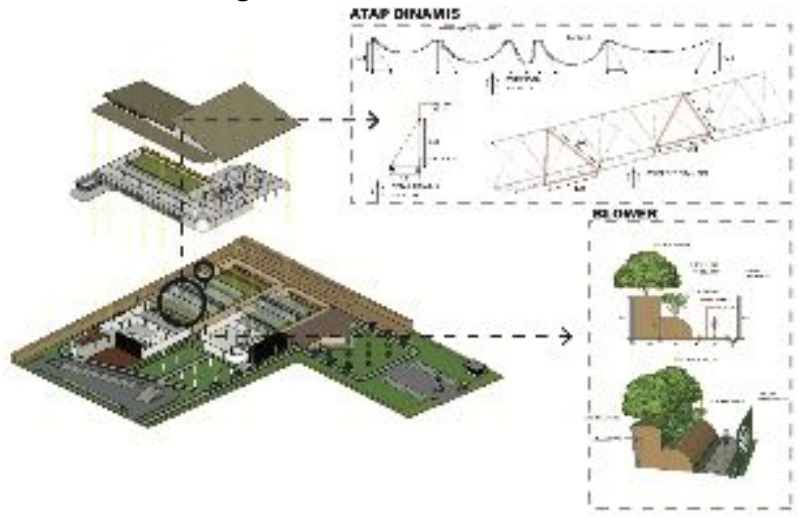

Gambar 13 Konsep Kognisi

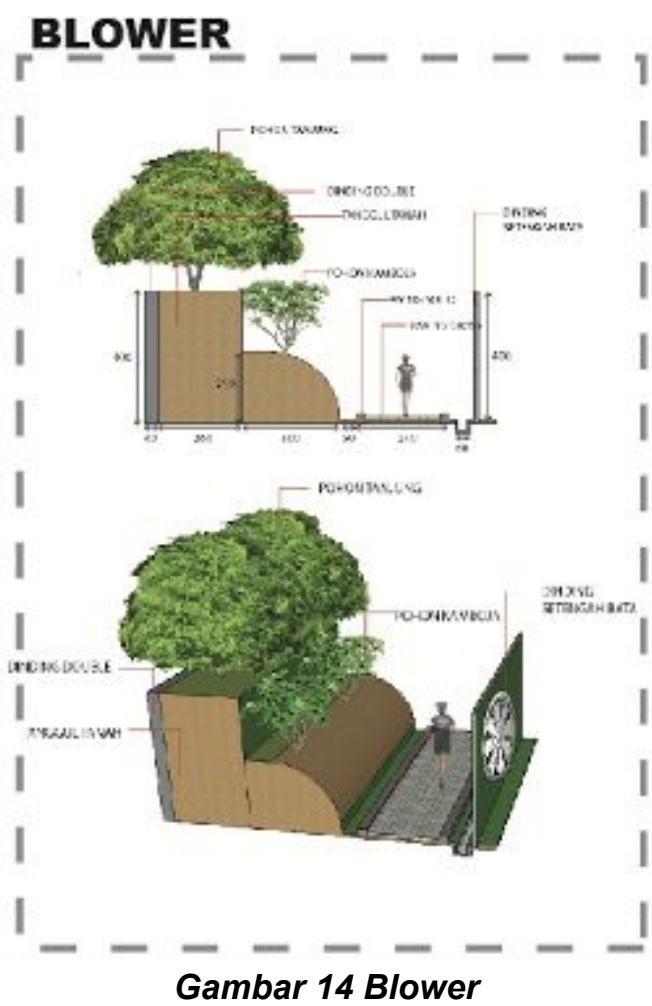

Sepanjang dinding bagian kanan dan kiri dinding lapangan $25 \mathrm{~m}$ dan $50 \mathrm{~m}$ terpasang blower agar dapat dinyalakan sesuai kebutuhan angina yang diperlukan.

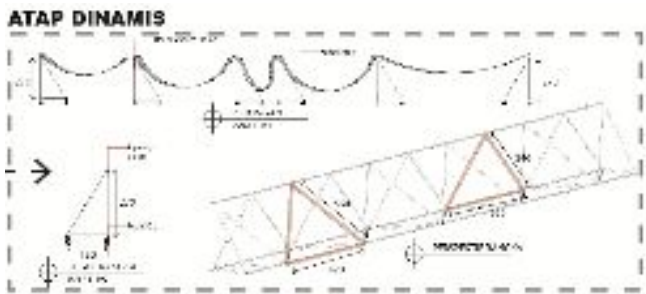

Gambar 15 Atap Dinamis

Atap dinamis pada area lapangan $25 \mathrm{~m}$ dan $50 \mathrm{~m}$ dibuat dengan rangka space frame dengan penutup tensile yang dapat digerakkan sehingga atap tersebut menutup seluruh bagian lapangan atau hanya sebagian.

\section{Konsep Zoning}

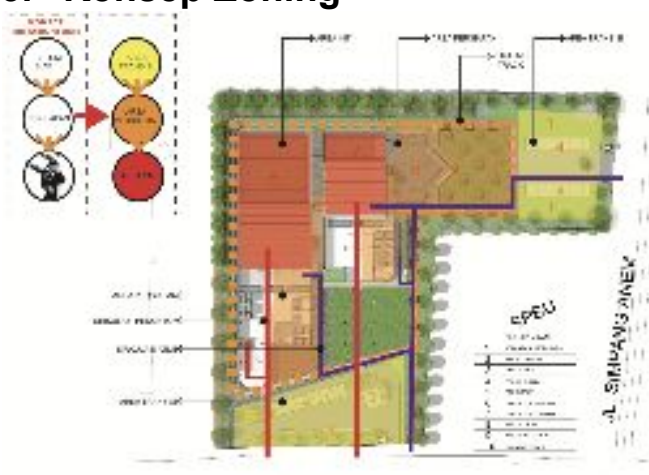




\section{Gambar 16 Konsep Zoning}

\section{Konsep Sirkulasi}

Sirkulasi penonton dan atlet dipisah agar para atlet tidak tercampur dengan penonton sehingga memecah konsentrasinya.

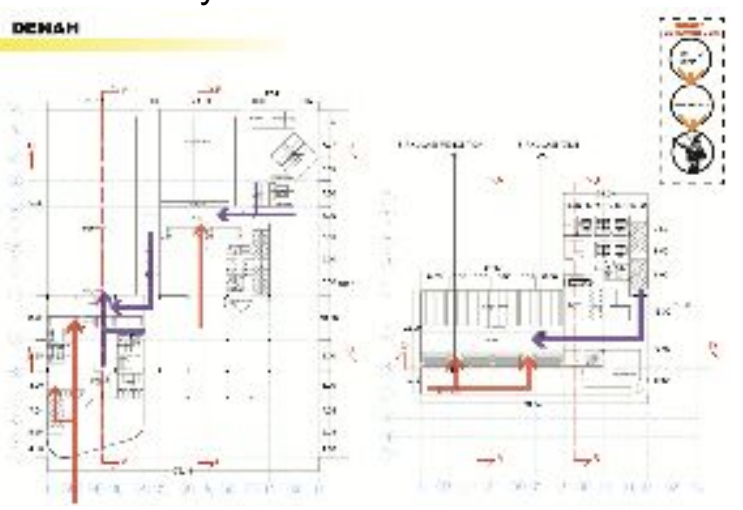

Gambar 17 Konsep Sirkulasi

\section{Konsep Landscape}

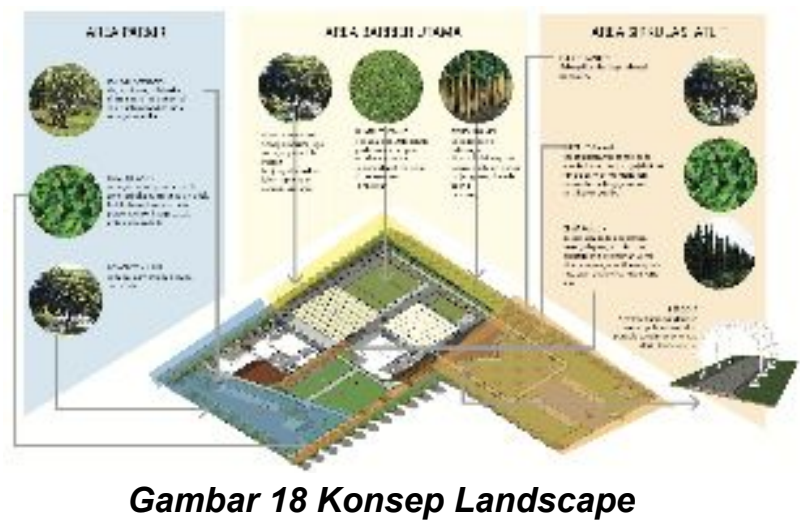

Pada area barrier utama terdapat tanggul dan leveling tanah agar mereduksi getaran dan bising dari dalam site. Juga terdapat pohon yang disusun lebih rapat sehingga mereduksi suara dari dalam site.

\section{Perancangan Tapak dan Bangunan}

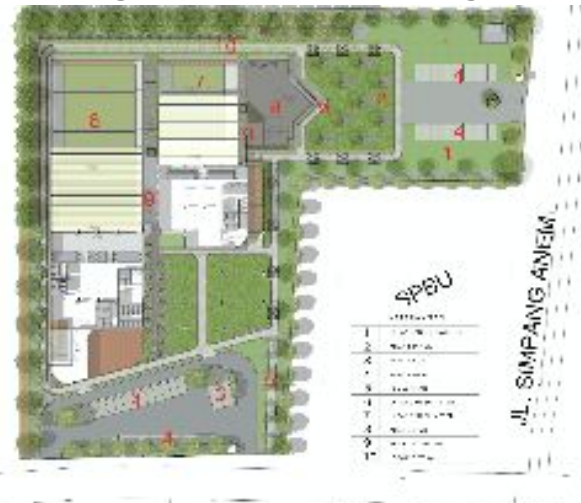

Gambar 19 Rencana Tapak
Akses utama site melalui Jalan Belitung Darat dan akses kedua yang diperuntukan untuk atlet dan pengelola melalui Jalan Simpang Anem.

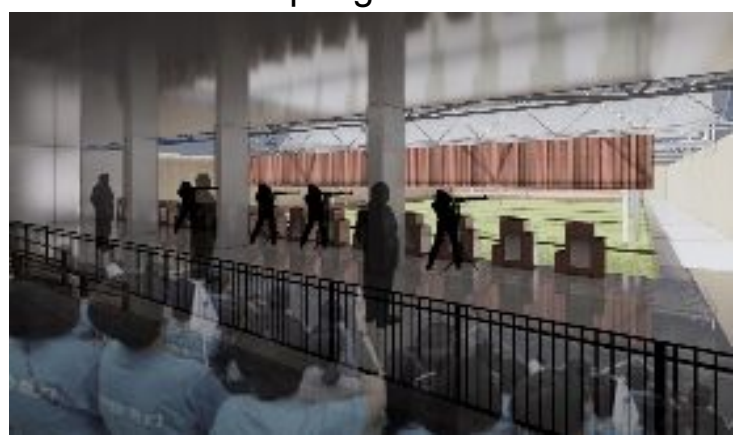

Gambar 20 Interior Lapangan 50 m

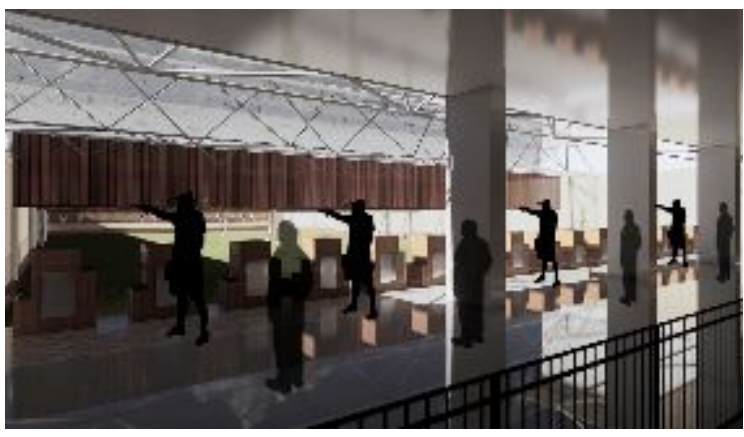

Gambar 21 Interior Lapangan 25 m

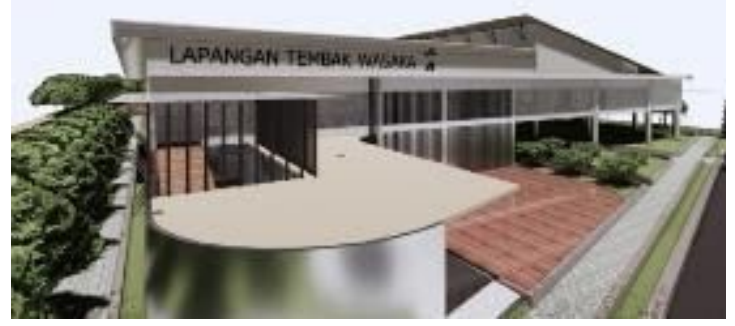

Gambar 22 Eksterior

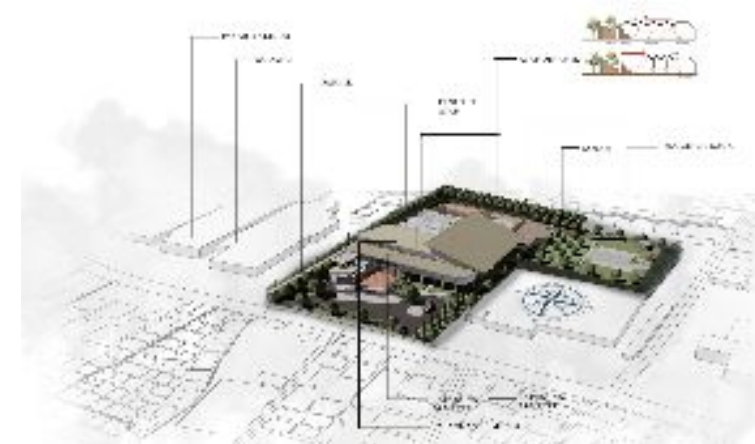

Gambar 23 Arial View 


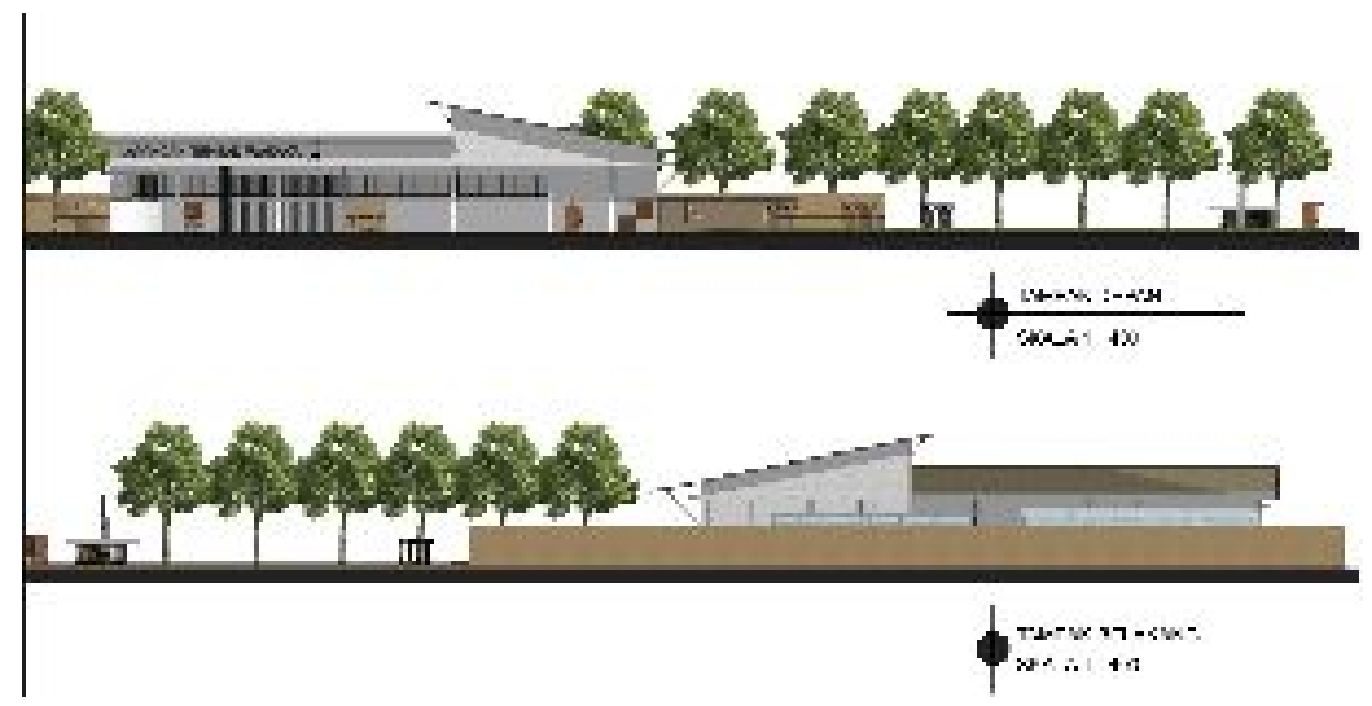

Gambar 24 Tampak

\section{KESIMPULAN}

Pengda Perbakin Kalimantan Selatan memiliki banyak atlet berpotensi namun tidak memiliki lapangan yang standar. Dikarenakan $90 \%$ atlet provinsi berdomisili di Banjarmasin maka site yang terpilih berlokasi di Jalan Belitung darat samping SPBU Belitung. Fasilitas yang memadai menjadi salah satu aspek penting untuk mendukung olahraga menembak secara optimal. Konsep Metamorfosis dipilih sebagai konsep pemecahan masalah yang dijadikan ide dasar desain Lapangan Tembak Wasaka dengan menggunakan Metode Arsitektur Perilaku. Perilaku atlet menembak menjadi dasar dari pemrograman ruang dengan mempertimbangkan kognisi, emosi, dan performance atlet sehingga program ruang akan terpicu dan tujuan dari perancangan akan tercapai. Berawal dari 3 bagian dari latihan berdasarkan dari psikologi olahraga lalu diolah menggunakan metode arsitektur perilaku yaitu emosi, kognisi dan performance. Konsep Metamorfosis dalam perancangan Lapangan Tembak Wasaka di Banjarmasin dapat membantu dalam mencapai tujuan dan pemecahan arsitektural yang diangkat dengan cara mengolah ruang dapat bergerak atau berubah menyesuaikan kondisi latihan yang diinginkan, memprogram ruang agar fokus atlet terjaga. Terdapat 3 zona yang berawal dari atlet belum siap menjadi siap. Serta beberapa titik silent exercise guna meredam emosi dari atlet juga secara kognisi.

\section{DAFTAR PUSTAKA}

Enzeta, Fachri dan Zulkarnain. 2016. Arsitektur Perilaku.

http://arsibook.blogspot.com/2016/11/arsitekt ur-perilaku.html diakses pada tanggal 11 Januari 2019 pukul 05:05 WITA

International Shooting Sport Federation. 2018. ISSF Shooting Venue Planning Guidelines. Edisi 2018.

International Shooting Sport Federation. 2018. Officials Statues Rules and Regulations. Edisi 2017.

Mazaya, Ulfa,. Setyawan, Wahyu,. 2016, Arsitektur Untuk Menyembuhkan Kerusakan Psikis Pada Manusia (Kekerasan Pada Anak), Jurnal Sains dan Seni Its Vol. 5, No.2, Surabaya : G-53.

Neufert, E. (1989). Data arsitek (Jilid 1) edisi kedua (Sjamsu Amril, Trans.). Jakarta: Penerbit Erlangga.

Neufert, E. (1989). Data arsitek (Jilid 2) edisi kedua (Sjamsu Amril, Trans.). Jakarta: Penerbit Erlangga.

Nugaradika, Arcadius Mahatma,. Suryawan, Wawan Ardiyan,. 2016, Arsitektur Perilaku : DPRD Bojonegoro, Jurnal Sains dan Seni Its Vol. 5, No.2, Surabaya : G-143

Supriyadi,. 2016, Psikologi Olahraga, Program Studi Psikologi Fakultas Kedokteran Universitas Udayana. Denpasar : 